ARTIG0

Recebido em: 08/03/2017

Aceito em: 25/06/2017

\title{
Privacidade, ética e informação: uma reflexão filosófica sobre os dilemas no contexto das redes sociais
}

\author{
Privacy, ethics and information: a philosophical reflection on the \\ informational ethics dilemmas in the context of social networks
}

\author{
Grace Quaresma FUGAZZA (gracefugazza@gmail.com)* \\ Gustavo Silva SALDANHA (saldanhaquim@gmail.com)** \\ * Bacharela em Biblioteconomia - UNIRIO. \\ ** Pesquisador - IBICT; Professor - UNIRIO/IBICT.
}

\begin{abstract}
Resumo
Este artigo objetiva refletir sobre os dilemas do direito à privacidade no contexto das redes sociais no âmbito da vivência da democracia no ciberespaço, problematizando a efetividade da garantia de proteção da privacidade dos internautas, na valorização dos princípios da liberdade e autonomia no ambiente da Internet. Indica as diversas legislações de escopos nacional e internacional que garantem o direito à privacidade e proteção de dados pessoais dos cidadãos. Revisa a literatura de ética informacional, associando este domínio do conhecimento ao conceito de privacidade e ao contexto das redes sociais, discutindo a construção de conceitos que norteiam e que estão diretamente envolvidos com os domínios afins. Considera, a partir dos aportes da filosofia da informação, que a personalização de conteúdos operacionalizada pelas empresas digitais, em troca da ampla liberdade de acesso aos dados pessoais de seus usuários, ameaça os princípios de autonomia e liberdade no ciberespaço. Observa que a investigação de dados pessoais é feita também entre os próprios indivíduos, como um reflexo da atual cultura de "transparência". Atenta para a necessidade de proteção ética e legal dos dados digitais dos internautas, visando à salvaguarda autônoma de sua identidade digital.
\end{abstract}

Palavras-chaves: Privacidade. Ética da informação. Redes sociais. Filosofia da Informação. Cultura digital.

\section{Abstract}

This article aims to reflect on the dilemmas of the right to privacy in the context of social networks regarding the experience of democracy in cyberspace, by problematizing the effectiveness of guaranteeing the protection of the privacy of Internet users, in the appreciation of the principles of freedom and autonomy in the Internet environment. It indicates the various national and international legislation that guarantee the citizens' right to privacy and protection of personal data. It reviews the literature of informational ethics, associating this domain of knowledge with the concept of privacy and the context of social networks, discussing the construction of concepts that guide and are directly involved with the domains of informational ethics. Critically considers that the customization of content operated by digital companies, in exchange for the broad freedom of access to the personal data of its users, threatens the principles of autonomy and freedom in cyberspace. It notices that the investigation of personal data is also done among individuals themselves, as a reflection of the current culture of "transparency". Highlights of the need for ethical and legal protection of the digital data of Internet users, aiming at the autonomous safeguarding of their digital identity.

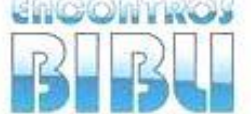

v. 22, n. 50,2017 p. $91-101$

ISSN 1518-2924
Keywords: Privacy. Information ethics. Social networks. Information Philosophy. Digital culture. 


\section{INTRODUÇÃo}

Estamos inseridos em uma cultura que favorece a transparência e, ao mesmo tempo, a não garantia da proteção da privacidade dos indivíduos no ambiente digital, constituindo um dilema central do mundo contemporâneo. 0 hábito de compartilhar (quase) tudo sobre a sua vida particular corresponde ao chamado oversharing, o abuso do fornecimento de dados pessoais nas plataformas de mídia na Internet. Este "supercompartilhamento" se intensifica com a utilização em massa de aparelhos celulares e outros dispositivos móveis aos quais se tem mais acesso hoje, pelo crescimento da classe consumidora, favorecido pelo barateamento do acesso à Internet.

Percebemos, assim, que as interações entre as pessoas no ambiente virtual se intensificam, atingindo patamares nunca antes alcançados. A vivência digital atinge hoje, segundo as análises da história da rede mundial de computadores, o contexto da chamada Web 2.0 ou semântica ${ }^{1}$, em que o foco é, justamente, a possibilidade de oferecer uma plataforma onde haja maior interação entre os usuários da rede. Hoje, qualquer indivíduo com acesso à Internet é potencialmente um emissor e receptor de conteúdo informacional, tarefa que antes era exclusiva do profissional jornalista.

Segundo Rafael Capurro (2009), isto representa a liberação do indivíduo para poder expressar-se autonomamente, sem recorrer a um intermediário. Entretanto, acreditamos que este cenário torna mais difícil identificar, reconhecer, discutir e apontar possíveis caminhos de resolução dos problemas éticos. Para fundamentar teoricamente o presente estudo, realizamos uma discussão a partir do aporte bibliográfico no contexto da ética da informação, a fim de interrelacionar e discutir três segmentos teóricos que estão no centro dos dilemas contemporâneos: o conceito de privacidade, a ética informacional e as redes sociais.

0 presente trabalho consiste em um estudo socioconceitual no contexto da filosofia da informação, isto é, representa uma reflexão teórica pautada na compreensão de determinados conceitos centrais para o pensamento biblioteconômico-informacional, como discutido em dilemas filosóficos lançados por Nélida González de Gómez, Michel Foucault, Daniel Nagel, Rafael Capurro, Bernd Frohmann, Ronald Day, Luciano Floridi, dentre outros.

Fundamentamos teoricamente este trabalho a partir do aporte teórico da ética da informação, concebida por Rafael Capurro. Esta pode ser entendida como uma reflexão aos novos desafios morais, relativos ao comportamento e às decisões de indivíduos na atualidade, desencadeados pelo desenvolvimento das Tecnologias da Informação e da Comunicação (TICs), em especial do conjunto de produtos e serviços da Internet.

A valorização da ideia de privacidade na ética informacional é caracteristicamente um valor moral que predomina nas culturas ocidentais, imbricada com os ideais democráticos que defendem os princípios de autonomia e liberdade. Quando adentramos as esferas políticas locais, percebemos o conjunto de problemas evocados pelo campo da ética no território das políticas de direito social e na participação cidadã crítica. Exemplo direto disto está na relação entre a atuação do Facebook e a Constituição brasileira, dentre outros confrontos éticos entre Mercado, Estado e Sociedade na contemporaneidade.

1 A Web Semântica é a Web de Dados, ou seja, ela atribui significados às informações na web, identificando-as e organizando-as, o que possibilita um ambiente de cooperação entre homens e máquinas. Disponível em: <http://tableless.com.br/a-web-semantica/>. Acesso em: 20 out. 2016. 


\section{OS DISCURSOS POR TRÁS DA ÉTICA INFORMACIONAL: MOTIVAÇõES DA REFLEXÃO A PARTIR DE CARTAS CONSTITUCIONAIS, PROJETOS DE REVISÃO E DECLARAÇÕES INTERNACIONAIS}

No Brasil, observamos na própria Constituição de 1988, artigo 5º, inciso X, que: "são invioláveis a intimidade, a vida privada, a honra e a imagem das pessoas, assegurado o direito a indenização pelo dano material ou moral decorrente de sua violação" (BRASIL, 1988); e no inciso XII do mesmo artigo que:

é inviolável o sigilo da correspondência e das comunicações telegráficas, de dados e das comunicações telefônicas, salvo, no último caso, por ordem judicial, nas hipóteses e na forma que a lei estabelecer para fins de investigação criminal ou instrução processual penal. (BRASIL, 1988)

O Marco Civil da Internet, Lei n. 12.965/2014, por sua vez, na definição dos direitos e deveres no uso da Internet no Brasil, garante em seu artigo 3ํㅡ, incisos II e III, respectivamente, a "proteção à privacidade" e a "proteção aos dados pessoais". Certamente a assertiva mais expressiva acerca da garantia da proteção da privacidade dos cidadãos encontra-se na Declaração Universal dos Direitos Humanos, das Nações Unidas, particularmente em seu artigo 19:

Toda pessoa tem direito à liberdade de opinião e expressão; este direito inclui a liberdade de, sem interferência, ter opiniões e de procurar, receber e transmitir informações e ideias por quaisquer meios e independentemente de fronteiras ${ }^{2}$. (UNITED NATIONS, 1948)

0 inciso I do artigo 8 da European Convention for the Protection of Human Rights and Fundamental Freedoms de 1950 garante que "todas as pessoas têm direito ao respeito da sua vida privada e familiar, do seu domicílio e da sua correspondência" (CONVENTION, 1950. Tradução nossa ${ }^{3}$ ). Nas Nações Unidas, o International Covenant on Civil and Political Rights de 1966 falava do direito do indivíduo à "autodeterminação" em seu artigo 1ํ. Legislações mais específicas de proteção dos dados pessoais são a Privacy Act de 1974 (EUA), a Bundesdatenschutzgesetz de 1978 (Alemanha), a European Union's Directive on Data Protection de 1995 (União Europeia), dentre outras. (FEATHER; STURGES, 2003)

No âmbito factual, alguns aspectos no ato de "privar informações" entram em confronto com o princípio de liberdade de informação. Esta consiste em um direito estatutário de acesso público à informação oficial, sendo concretizada na forma das leis FOI (Freedom of Information Act), que garantem o acesso aberto às diversas informações que concernem à população. (FEATHER; STURGES, 2003)

No Brasil, essa prática está consolidada sob a Lei de Acesso à Informação (Lei no 12.527/2011), que consiste em um direito constitucional para garantir o acesso às informações públicas. A lei prevê que todos os cidadãos possam receber informações públicas dos órgãos e entidades.

Os dilemas em torno de questões para além da privacidade, como confidencialidade de dados, censura, direitos do autor, liberdade intelectual versus direitos de cópia (copyright), entre outros estudados pela ética informacional, são especialmente preocupantes para os profissionais da Biblioteconomia \& Ciência da Informação, gestores de unidades de informação, bibliotecários e afins. Assim, a

\footnotetext{
2 "Everyone has the right to freedom of opinion and expression; this right includes freedom to hold opinions without interference and to seek, receive and impart information and ideas through any media and regardless of frontiers." (UNITED NATIONS, 1948)

3 "everyone has the right to respect for his private and family life, his home and his correspondence."
} 
investigação deste domínio complexo e urgente contribui para um melhor entendimento do objeto de estudo do campo biblioteconômico-informacional, qual seja: a informação, no que tange à sua segurança e garantia de sua proteção, seu uso e suas consequências.

\section{NO TERRITÓRIO DA ÉTICA INFORMACIONAL}

O domínio da ética informacional possui grande relevância no que tange ao reconhecimento dos direitos humanos em uma época de concentração intensiva do uso das TICs e, em especial, da Internet. Assim, a necessidade de proteger tais direitos no âmbito das tecnologias digitais se faz latente nas sociedades modernas. A European Convention for the Protection Human Rights and Fundamental Freedoms reconhece como valores inalienáveis a proteção do direito à vida, a proibição da tortura e da escravidão e a liberdade, dentre outros. 0 direito de exigir respeito pela vida privada e pela vida em família, representando uma garantia da liberdade do indivíduo em escolher como interagir com os outros em um mundo compartilhado, também está incluso nos princípios básicos da Convenção.

Rafael Capurro, na defesa de que as experiências digitais sofrem do que o filósofo chama de "colonialismo" e "opressão cultural" em prol do lucro corporativo, concebe uma ética intercultural da informação. Ela enunciaria uma "programação ética transcultural e prescritiva", na ausência de parâmetros únicos e fixos na definição das diversas morais. Far-se-ia necessário, segundo o autor, a criação de um "arcabouço institucional (jurídico e político)" em que estariam representados os conflitos e reflexões das diversas tradições culturais. (GONZÁLEZ DE GÓMEZ, 2009)

A ética intercultural da informação se preocupa com questões as mais diversas conforme a cultura com a qual lida. Tais questões são de natureza ética e surgem no bojo do desenvolvimento das TICs. São os problemas advindos de temas como os direitos do autor e propriedade intelectual em geral; liberdade de expressão; censura; nos casos de governos autoritários ou semi democráticos, a tecnologia como um meio de protesto político e/ou de repressão social; a questão da exclusão digital por grande parcela da população devido à ausência de condições econômicas; o uso excessivo dos meios tecnológicos, em especial por uma geração que já nasceu num mundo digital, resultando em segregação social ou educacional; o vício nas tecnologias; a proteção da privacidade dos cidadãos como uma responsabilidade do Estado no âmbito da segurança pública. (CAPURRO, 2009)

0 atual contexto no ciberespaço é o de crescente fornecimento de dados pessoais tanto às empresas digitais, quanto à rede de usuários à qual o indivíduo está conectado. A proteção da privacidade é uma das questões de natureza ética que surgem neste âmbito.

Vivemos em uma época que exige uma flexão ou uma plasticidade interativa da racionalidade a partir da qual possamos enfrentar o universo das novas questões éticas, políticas e legais que se acumulam diariamente nas práticas científicas, empresariais, sociais e governamentais, na vida pública e na vida privada (FREIRE, 2010, p. 6)

Freire (2010) acrescenta que a confidencialidade dos dados; a segurança das informações; a prática do spamming; a desumanização do usuário decorrente da impessoalidade ou "despersonalização" da vida virtual; a divulgação de informações incriminatórias para acusar um indivíduo suspeito de cometer delitos; são outras questões preocupantes surgidas no contexto das tecnologias digitais, e estudadas pela ética da informação. 


\subsection{Privacidade \& ética informacional}

Ter sua privacidade protegida significa, na cultura ocidental, possuir autonomia. Rainer Kuhlen (apud CAPURRO, 2005) entende a privacidade fundamentalmente sob a denominação "autonomia informacional", que consiste no poder de escolha do indivíduo acerca do uso da informação em um ambiente eletrônico. Assim, o indivíduo deve gozar de liberdade no processo que abarca desde a busca, a seleção, até ao uso da informação. A partir do momento em que a autonomia dos indivíduos é infringida, tem-se a violação de sua própria liberdade. Isto porque, segundo Beate Rössler, "a autonomia de proteção da privacidade é a base da liberdade, e não o contrário" (RÖSSLER, apud CAPURRO; ELDRED; NAGEL, 2012, p. 79. Tradução nossa ${ }^{4}$ ). De acordo com a autora (respaldada em Mill e Rorty), uma vida que não seja determinada pelo próprio indivíduo consiste na infração da sua "privacidade decisional". Para Luciano Floridi (apud CAPURRO; ELDRED; NAGEL, 2012), a privacidade da informação está atrelada ao próprio direito à vida e à liberdade. "Privacidade informacional se torna 'um direito fundamental e inalienável' semelhante ao direito à vida e à liberdade" (FLORIDI, apud CAPURRO; ELDRED; NAGEL, 2012, p. 109. Tradução nossa5).

Floridi (1999) defende a ideia de que a informação pessoal de cada pessoa está intimamente associada à sua concepção de identidade. Nossos dados seriam, dessa forma, "um pedaço de nós mesmos". Uma vez que minhas informações são tornadas públicas, elas deixam de ser controladas por mim (a quem pertencem), e passam a ser um "pedaço morto de mim mesmo que foi entregue ao mundo" (FLORIDI, 1999. Tradução nossa ${ }^{6}$ ). De acordo com o autor, a fonte dos problemas sociais oriundos do (mau) uso das tecnologias digitais não está nas suas consequências, nem mesmo nas rejeições das morais acerca das questões de privacidade pessoal, mas sim na falta de cuidado e respeito para com o indivíduo e, consequentemente, para com a sua informação.

0 motivo deste fenômeno seria, segundo Floridi (ibid.) o de que os dados privados associados a um indivíduo, na chamada infosfera, são vistos como "pacotes de informação", em que os indivíduos seriam reduzidos a números e meras coleções de informação, de forma que os seres humanos seriam tratados como "entidades informacionais". Floridi vê, então, a privacidade pessoal como uma defesa das informações dos indivíduos (informações estas que seriam parte constituinte do seu próprio ser), a fim de evitar um processo de alienação que o autor defende como sendo característico da invasão dessa privacidade.

0 autor observa que tanto a invasão da privacidade quanto muitos outros problemas éticos advindos do (mau) uso das TICs e, especialmente, da Internet, possui uma natureza lúdica, o que ocasionaria em uma difusão de responsabilidade. Isto significa que, uma vez que a informação no ambiente digital é de natureza imaterial e o próprio ambiente possibilita a interação remota com "indivíduos sem rosto", os crimes praticados na infosfera não são percebidos pelos seus praticantes como algo prejudicial, uma vez que o ciberespaço é visto como diferente do mundo real. Os internautas, atuando em um "ambiente irreal", poderiam ver a informação

\footnotetext{
4 "Privacy-protecting autonomy is the basis of freedom, not the other way round."

5 "Informational privacy becomes 'a fundamental and inalienable right' akin to the right to life and liberty."

6 "[...] it is transformed into a dead piece of my self that has been given to the world [...]."
} 
também como irreal. Portanto, os motivos que causam os cibercrimes ${ }^{7}$ (invasão de privacidade, inclusive) estão atrelados ao que Floridi denominou de "difusão de responsabilidade".

Outro olhar acerca da questão da privacidade é apresentado por Rubens da Silva Ferreira (2014), que adota a concepção de sociedade disciplinar de Michel Foucault a partir da obra "Vigiar e punir" (2013), para abordar a questão da disciplina, do controle e da vigilância como realidades na sociedade da informação contemporânea. Para Ferreira (2014), o discurso otimista e utópico da sociedade da informação, que proporcionaria um senso de autoformação e autoaprendizado nos indivíduos, esconderia outra realidade: um "autodisciplinamento" entre as pessoas na referente sociedade informacional.

Isto ocorre devido à passagem do poder de disciplina e vigilância alçada das instituições para as mãos dos próprios indivíduos vigiados. Hoje, o ato de disciplinar, controlar e vigiar pertence aos próprios indivíduos. Estes o fazem tanto para a comunidade, quanto para consigo mesmos. (FERREIRA, 2014). Assim, de acordo com o autor, existiria nas sociedades modernas, tendo a Internet como um espaço cada vez mais consolidado das relações sociais, um "novo regime de vigilância". O constante olhar sobre as atividades e o comportamento do outro e de si mesmo, além do intenso controle que as empresas digitais possuem dos nossos dados, marcaria as dinâmicas do ciberespaço, no jogo entre sociedade de vigilância, pela via foucaultiana, e sociedade de controle, ou de vigilância invisível, pela via deleuziana.

\subsection{Privacidade \& ética informacional no contexto das redes sociais}

A corrida em prol do lucro marca os bastidores das interfaces das redes sociais. Corporações com fins lucrativos, redes sociais como o Facebook adotam estratégias de negócios para atrair a atenção dos usuários para os seus produtos e serviços. Segundo Eli Pariser, ativista político e cibernético, em seu livro "O filtro invisível" (2012), essas corporações conquistam a fidelidade dos internautas por meio da personalização e filtragem de conteúdo. Isto é feito através da solicitação e análise dos dados pessoais de seus usuários (a partir da utilização de tecnologias como os cookies e beacons ${ }^{8}$ ).

Uma vez reunido privacidade. Aqui o filósofo o maior número possível de informações sobre seus usuários, essas corporações desenvolvem algoritmos de personalização para direcionar anúncios, serviços e experiências digitais aos usuários adequados, a partir de uma análise do seu perfil, potencializando assim as suas vendas. "A tentativa de saber o máximo possível sobre seus usuários tornou-se a batalha fundamental da nossa era entre gigantes da Internet como Google, Facebook, Apple e Microsoft." (PARISER, 2012, p. 12).

0 autor defende que o problema reside no momento em que essas empresas digitais utilizam os dados dos usuários sem o consentimento dos mesmos e, em casos mais extremos, de forma a prejudicá-los de alguma maneira. 0 contrato legal

\footnotetext{
7 São diversos os crimes informáticos que preocupam as autoridades nos dias atuais. Alguns exemplos são o plágio, o hackeamento, o roubo de identidade, a perseguição virtual, o assédio online, a invasão de privacidade, dentre outros. Disponível em: <http://www.enigmasoftware.com/pt/5-cibercrimespopulares-como-evita-los-facilmente/>. Acesso em: 15 out. 2015.

${ }^{8}$ Cookies são arquivos de texto que armazenam as preferências dos usuários através de vários sites. Os web beacons permitem que os sites coletem e transfiram informações aos usuários, quando estes clicam em alguma imagem. Estas tecnologias são instrumentos de rastreamento utilizados pelos sites para conhecer os perfis de usuário. Disponível em: $<$ http://seguranca.uol.com.br/antivirus/dicas/curiosidades/privacidade-na-internet-conheca-oscookies-web-beacons-e-flash-cookies.html\#rmcl>. Acesso em: 15 out. 2016.
} 
existente entre as corporações digitais (redes sociais, inclusive) e os usuários são os termos de uso, onde se tem acesso às políticas de privacidade, políticas de cookies, uso dos dados fornecidos etc.

A personalização se baseia numa barganha. Em troca do serviço de filtragem, damos às grandes empresas uma enorme quantidade de dados sobre nossa vida diária [...]. Essas empresas estão ficando cada vez melhores no uso desses dados para traçar suas estratégias. No entanto, muitas vezes acreditamos excessivamente que essas empresas irão cuidar bem dessas informações, e, quando nossos dados são usados para tomar decisões que nos afetam negativamente, em geral não ficamos sabendo. (PARISER, 2012, p. 20)

Os argumentos de "Vigiar e punir" de Michel Foucault (2013) representam um importante aporte para o problema da invasão da privacidade, em que o filósofo faz referência ao instrumento do Panóptico ${ }^{9}$ como uma representação do poder de vigilância na vida dos cidadãos. Para Foucault, a ideia do "olho que tudo vê" do Panóptico pode ser adaptada a qualquer tipo de poder onde se observa uma relação de vigilância de uma determinada entidade para com as pessoas.

E para se exercer, esse poder deve adquirir o instrumento para uma vigilância permanente, exaustiva, onipresente, capaz de tornar tudo visível, mas com a condição de se tornar ela mesma invisível [...] milhares de olhos postados em toda parte, atenções móveis e sempre alerta, uma longa rede hierarquizada [...]. E essa incessante observação se deve acumular numa série de relatórios e de registros [...] uma tomada de contas permanente do comportamento dos indivíduos (FOUCAULT, 2013, p. 202).

Ferreira (2014), respaldando-se nesta concepção de sociedade disciplinar de Foucault (2013), afirma que a vigilância na contemporaneidade assumiu uma forma através do setor privado. É possível observar esta aplicação na maneira como as empresas digitais lidam com as informações dos internautas, visto que elas possuem grande liberdade de acesso às informações dos usuários da Internet e, principalmente, dos usuários que utilizam os seus serviços ${ }^{10}$.

Os conceitos de autonomia, individualidade e privacidade, hoje, são transformados, segundo Rafael Capurro (2005), em "individualidades conectadas". 0 autor afirma que "ser-no-mundo" está se igualando, na contemporaneidade, à ideia de "ser-no-mundo-compartilhado". Assim é concebida a noção da ética do conhecimento compartilhado. De fato, o autor diz haver uma contiguidade quanto ao compartilhamento no mundo não digital e no digital. Na visão do autor, um mundo não termina quando o outro começa, mas se alternam constantemente (CAPURRO, 2016). Isto é visto também por Eldred (2012) quando este diz que os limites entre ambos os mundos estão cada vez mais indefinidos. Suas interfaces são, na verdade, interligadas.

As interfaces humanas com o mundo cibernético o tornam apto como uma luva, de modo que as fronteiras entre o ser-no-mundo cibernético e o ser-no-mundo-físico tornam-se cada vez mais indefinidas. [...] Os dois se entrelaçam perfeitamente em um ser-no-

\footnotetext{
9 O Panóptico foi concebido pelo jurista e filósofo inglês Jeremy Bentham (1843) para se referir a uma matriz arquitetônica de controle e vigilância nas instituições prisionais dos meados do século XIX. (FERREIRA, 2014)

10 Esta informação pode ser constatada no próprio termo de uso do Facebook, cuja leitura e aceitação pelo usuário consistem em condições para o mesmo se cadastrar no site.
} 
mundo cotidiano unificado. ${ }^{11}$ (CAPURRO; ELDRED; NAGEL, 2012, p. 92. Tradução nossa)

Rafael Capurro (2005) observa que o debate em torno da privacidade fomentou medidas de segurança no Ocidente principalmente a partir da ameaça de ataques terroristas suscitada com o 11 de setembro, nos Estados Unidos. A proteção da privacidade, inserida no contexto de uma sociedade de controle, é desencadeada pelo desenvolvimento da comunicação em rede, em especial por meio dos aparelhos celulares. $\mathrm{O}$ autor afirma que, "como hoje vivemos em um ambiente digital, proteger a privacidade individual significa fundamentalmente proteger nossos dados digitais." (CAPURRO, 2005. Tradução nossa ${ }^{12}$ ).

Michael Eldred (CAPURRO; ELDRED; NAGEL, 2012, p. 66), entende a privacidade no âmbito da fenomenologia da identidade (do inglês, whoness). Esta é concebida como um fenômeno onde a pluralidade dos seres humanos se exibe uns aos outros num mundo compartilhado. Tal exibição acerca de quem as pessoas são diz respeito a como elas se exibem. Para tanto, elas usam o que o autor chama de "máscaras de habilidade" (adotam certo comportamento, usam determinadas roupas etc.), no intuito de serem vistas da maneira como elas se apresentam e, de certa forma, desenvolver o seu poder pessoal no mundo.

A "personalidade pública" (public persona) do indivíduo, qual seja, a máscara que este indivíduo apresenta aos outros acerca de quem ele é, recebe certa reputação, referente ao quão estimada é a pessoa ao longo dos anos. Ética, no entendimento de Eldred (ibid.), significa viver em concordância com o ethos de um estilo de vida compartilhado ao longo da história por um povo. Isto implica que um dano à reputação de um indivíduo corresponde a um ataque à sua vida privada. Com a Internet, as possibilidades de revelar sua identidade cresceram exponencialmente, assim como as formas de rastrear as atividades digitais que se queira recuperar através de uma consulta à matriz da rede, que registra todo e qualquer movimento digital; tornando mais fácil ferir a reputação de alguém.

Assim como cresceram as formas de autoapresentação no ciberespaço, também as ações que ocasionam os cibercrimes possuem mais "chances" de serem eficazes no ambiente digital do que no não digital. Isto porque, segundo Eldred (ibid.), toda ação no ciberespaço é melhorada quando comparada com as ações no mundo físico. 0 autor ainda nos fornece a concepção de que a nossa identidade digital consiste em responder à questão acerca do que somos no ciberespaço. Ele afirma que, neste contexto, somos nossos dados digitais; e que são estes os que necessitam de proteção ética e legal. "O direito de ser deixado em paz" (CAPURRO; ELDRED; NAGEL, 2012) está, então, associado à proteção da privacidade no âmbito do ciberespaço.

Daniel Nagel (ibid., p. 124) diz que a liberdade do indivíduo pressupõe que o mesmo possua oportunidades de escolher como, quando e onde deseja revelar a sua identidade em um mundo compartilhado, e que esta questão é inclusive uma preocupação do Estado no que concerne à segurança nacional. 0 direito à privacidade pessoal e familiar significa, de acordo com o autor, um indivíduo gozar de liberdade para decidir tanto a maneira como deseja revelar quanto esconder a si mesmo e as suas informações. Esta liberdade abrange também o poder de escolha acerca de como o indivíduo deseja interagir com outros em um mundo cada vez

11 "The human interfaces with the cyberworld make it fit like a glove, so that the borders between being-in-the-cyberworld and being-in-the-physical-world become increasingly blurred. [...] The two intermesh seamlessly into a unified everyday being-in-the-world."

12 "Given that we live today in a digital environment - to protect individual privacy means primarily to protect our digital data." 
mais conectado e compartilhado.

\section{CONSIDERAÇÕES FINAIS}

Consideramos, no contexto dos atuais dinamismos interativos característicos da Web 2.0 ou semântica (e, mais recentemente, a Web 3.0), somado à facilidade de acesso aos dispositivos tecnológicos, mais especificamente ao conjunto de produtos da Internet, que a questão da proteção da privacidade é tão latente em nossa sociedade quanto os movimentos pela ampliação do acesso à Rede Mundial de Computadores.

Percebemos que a agenda do direito à proteção à privacidade na Internet não ganha a visibilidade devida diante dos crescentes problemas envolvendo esta temática na contemporaneidade; diferentemente do que ocorre, por exemplo, com os movimentos em prol da ampliação de acesso à rede. Isto é agravado diante da realidade de ações estratégicas de personalização e filtragem de conteúdo operacionalizadas pelas empresas digitais para potencialização do lucro corporativo, facilitando sobremaneira o amplo acesso que elas possuem sobre as informações dos internautas, o que limita as possibilidades de liberdade e autonomia neste ambiente.

Consideramos, sob essas circunstâncias, que as experiências digitais dos internautas não podem ser caracterizadas pelos princípios da liberdade e autonomia, visto que a sua privacidade não é tratada como prioridade pelas empresas digitais. Observamos que tais empresas dão atenção ao fenômeno da questão do direito à privacidade, mas estariam preocupadas, essencialmente, com o desenvolvimento de estratégias de marketing com finalidades de lucro, em um jogo controverso entre transparência e ausência de privacidade. Além disso, considerando-se a realidade de uma cultura de transparência em um mundo cada vez mais conectado e compartilhado, observa-se que os internautas possuem o hábito de investigar (e avaliar) os dados privados, atividades e comportamentos uns dos outros, ultrapassando a noção de que as ações de controle e vigilância invisível das redes partiriam apenas das empresas, estando presentes também entre os próprios indivíduos.

Tais condicionantes são um reflexo da atual cultura de transparência no contexto de uma sociedade disciplinar pelo setor privado contemporânea, que coloca em questão uma centralidade da filosofia da informação, ou seja, uma ética que se proponha pensar e abordar criticamente os conflitos morais de um "ser-nomundo-informacional". Nesta sociedade, as figuras opressoras das instituições punitivas e controladoras tornam-se dispensáveis, uma vez que agora as pessoas assumem o papel de sentinelas e carrascos umas das outras e de si mesmas.

Cabe exclusivamente ao indivíduo a escolha acerca de quando, como e o que revelar e/ou ocultar as informações de sua vida privada e as de sua família, e a não garantia deste direito é assunto que concerne diretamente ao Estado. Visto que os dados pessoais consistem na própria identidade digital dos usuários da Internet, fazse necessário a garantia da proteção, tanto ética quanto legal, de tais dados, a fim de proteger a identidade digital dos internautas. Dada a capilaridade e a velocidade das dinâmicas digitais, o debate filosófico aqui lançado torna-se central para a construção de um discurso ético crítico no território informacional.

\section{AGRADECIMENTOS}

CNPq; FAPERJ; UNIRIO; IBICT. 


\section{REFERÊNCIAS}

BRASIL. Constituição (1988). Constituição da República Federativa do Brasil de 1988. Brasília, DF: Senado Federal: Centro Gráfico, 1988. 292 p.

Lei no 12.527, de 18 de novembro de 2011. Regula o acesso a informações previsto no inciso XXXIII do art. 5ํㅡ, no inciso II do § 3o do art. 37 e no § 20 do art. 216 da Constituição Federal. Diário Oficial da União. Poder Executivo, Brasília, DF, 18 nov. 2011. Seção 1, p. 12.

CAPURRO, Rafael. Ética intercultural de la información. In: GOMES, Henriette Ferreira; BOTTENTUIT, Aldinar Martins; OLIVEIRA, Maria Odaisa Espinheiro de. (Org.). A ética na sociedade, na área da informação e da atuação profissional: o olhar da Filosofia, da Sociologia, da Ciência da Informação e da formação e do exercício profissional do bibliotecário no Brasil. Brasília, DF: Conselho Federal de Biblioteconomia, 2009. p. 43-64. Disponível em: <http://www.cfb.org.br/popup/a_etica.pdf>. Disponível em: 25 jun. 2016.

. Impactos de las tecnologías digitales de la información y comunicación en la filosofía, las artes y las ciencias. Perspectivas UNICAMP 50 anos. Mesa: Impactos das Tecnologias da Informação na Filosofia, nas Artes e na Ciência. Anais eletrônicos... Campinas: UNICAMP, 2016. Disponível em: <http://www.capurro.de/campinas.html>. Acesso em: 22 set. 2016.

Privacy: An Intercultural Perspective. Ethics and Information Technology, v. 7, 2005, p. 37-47. Disponível em: <http://www.capurro.de/privacy.html>. Acesso em: 24 jun. 2016.

CAPURRO, Rafael; ELDRED, Michael; NAGEL, Daniel. It and privacy from an ethical perspective digital whoness: identity, privacy and freedom in the cyberworld. In: BUCHMANN, Johannes (Ed.). Internet Privacy: a multidisciplinary analysis. München: Acatech, 2012. Disponível em: <http://www.acatech.de/fileadmin/user_upload/ aumstruktur_nach_Website/Acatech/root/de/Publikationen/Projektberichte/ acatech_STUDIE_Internet_Privacy_WEB.pdf>. Acesso em: 11 out. 2016.

CONVENTION for the Protection of Human Rights and Fundamental Freedoms.

European Convention on Human Rights. European Court of Human Rights. Council of Europe. Rome, 04 nov. 1950. Disponível em: <http://www.echr.coe.int/Documents/ Convention_ENG.pdf>. Acesso em: 23 jun. 2016.

DELEUZE, Gilles. Post-scriptum sobre as sociedades de controle. In.: Conversações: 19721990. Rio de Janeiro: Ed. 34, 1992. p. 219-226.

FEATHER, John; STURGES, Paul (Ed.). International Encyclopedia of Information and Library Science. 2. ed. London: Routledge, 2003.

FERREIRA, Rubens da Silva. A sociedade de vigilância como sociedade de disciplina, vigilância e controle. Información, cultura y sociedad, Buenos Aires, n. 31, dez. 2014. Disponível em: <http://www.scielo.org.ar/scielo.php?script=sci_ arttext\&pid=S185117402014000200007>. Acesso em: 29 ago. 2016.

FLORIDI, Luciano. Information ethics: On the philosophical foundation of computer ethics. Ethics and Information Technology, v. 1, n. 1, p. 33-52, mar. 1999.

FOUCAULT, Michel. Vigiar e punir: história da violência nas prisões. 41. ed. Petrópolis: Vozes, 2013.

FREIRE, Gustavo Henrique de Araújo. Sobre a ética da informação. In: SIMPÓSIO BRASILEIRO DE ÉTICA DA INFORMAÇÃO, 1., 2010, João Pessoa. Ética da informação: conceitos, abordagens, aplicações. Organização de Gustavo Henrique de Araújo Freire. João Pessoa: 
Ideia, 2010. p. 5-10. Disponível em:

<http://ru.ffyl.unam.mx:8080/bitstream/10391/1328/1/teaching\%20information\%20eth ics.pdf>. Acesso em: 26 jun. 2016.

GONZÁLEZ DE GOMEZ, Maria Nélida. Desafios contemporâneos da ciência da informação: as questões éticas da informação. In: ENCONTRO NACIONAL DE PESQUISA DA ASSOCIAÇÃO NACIONAL DE PESQUISA E PÓS-GRADUAÇÃO EM CIÊNCIA DA INFORMAÇÃO, 10., 2009, João Pessoa. Responsabilidade social da Ciência da Informação [trabalhos apresentados] Organização de Gustavo Henrique de Araújo Freire. João Pessoa: UFPB, 2009. p. 106-126. Disponível em: <http://enancib.ibict.br/index.php/enancib/xenancib/paper/viewFile /3133/2259>. Acesso em: 29 jun. 2016.

INTERNATIONAL Covenant on Civil and Political Rights. United Nations. Human Rights. 16 dec. 1966. Disponível em: <http://www.ohchr.org/en/professionalinterest /pages /ccpr.aspx>. Acesso em: 23 jun. 2016.

PARISER, Eli. 0 filtro invisível: o que a internet está escondendo de você. Rio de Janeiro: Zahar, 2012.

UNITED NATIONS. The Universal Declaration of Human Rights. Paris. 10 dec. 1948. Disponível em: <http://www.un.org/en/universal-declaration-human-rights/>. Acesso em: 07 jul. 2016. 